\title{
Genome and MIC stability in Mycobacterium tuberculosis and indications for continuation of use of isoniazid in multidrug-resistant tuberculosis
}

\author{
T. C. VICTOR, R. WARREN, J. L. BUTT, A. M. JORDAAN, J. V. FELIX, A. VENTER, F. A. SIRGEL, \\ H. S. SCHAAF*, P. R. DONALD*, M. RICHARDSON, M. H. CYNAMON† and P. D. VAN HELDEN \\ MRC Centre for Molecular and Cellular Biology, Department of Medical Biochemistry, *Paediatrics and Child \\ Health, Tygerberg Hospital and the University of Stellenbosch, PO Box 19063, Tygerberg 7505, South Africa \\ and + Veterans Affairs Medical Center, Syracuse, USA
}

\begin{abstract}
Mycobacterium tuberculosis strains resistant to two or more of the first line antituberculosis drugs (MDR) are a serious threat to successful tuberculosis control programmes. For this retrospective study, 85 follow-up drug resistant isolates from 23 patients residing in a community with a high incidence of tuberculosis were collected and the level of in-vitro resistance to antibiotics determined quantitatively. PCR-SSCP and sequencing techniques were used to screen for gene mutations associated with resistance in 31 follow-up samples from a smaller group of eight patients. DNA fingerprint analysis was done on sequential isolates to confirm identity. Although treatment had a profound effect on changes in drug resistance patterns, the MIC for a particular agent remained constant in follow-up isolates. DNA fingerprinting and mutational analysis (14 different loci) showed that the genome of MDR strains of $M$. tuberculosis is relatively stable during the course of therapy. The rpoB gene was the most frequently mutated structural gene involved in drug resistance and a novel $\mathrm{C}$ to $\mathrm{T}$ mutation upstream of open reading frame (ORF)1 of the $i n h A$ operon was detected. No evidence was found of the presence of strain W (New York) in this group of MDR strains. The results stress the importance of confirming individuality of strains for the accurate calculation of frequencies of particular mutations associated with drug resistance, particularly in a high incidence area. Approximately one-half $(\mathbf{4 7 . 8 \% )}$ of the patients had isolates resistant to concentrations just above the critical concentration for isoniazid (MICs of $0.2-5 \mathrm{mg} / \mathrm{L}$ ). Therefore, these patients and their contacts who develop primary drug-resistant tuberculosis may respond to higher dosages of treatment which could have a considerable impact on the cost and the ease of management of resistant tuberculosis.
\end{abstract}

\section{Introduction}

A recent resurgence in the incidence of tuberculosis in developed and developing countries, linked partly to the human immunodeficiency virus (HIV) pandemic, has re-awakened public concern. Strains resistant to one or more of the major antituberculosis drugs threaten tuberculosis control programmes in developing and developed countries. Multidrug-resistant (MDR) strains have been associated with rapid progression to death of HIV-infected individuals $[1,2]$ and transmission of MDR strains to health care personnel is an added cause for concern.

Received 24 Oct. 1996; revised version received 18 Feb. 1997; accepted 19 Feb. 1997.

Corresponding author: Dr T. C. Victor.
Streptomycin (SM) was the first drug shown to be effective in the treatment of tuberculosis [3]. However, monotherapy led to the selection of resistant strains of Mycobacterium tuberculosis [4] and subsequently combination chemotherapy was shown to prevent the development of drug resistance. A combination of isoniazid (INH), rifampicin (RMP) and pyrazinamide (PZA) (the first-line drugs) is currently used with success in short course chemotherapy of tuberculosis. Various other drugs, such as SM or other aminoglycosides, ethionamide (ETH), ethambutol (EMB), thiacetazone (TH) and cycloserine (CS) are considered as alternatives for the management of MDR tuberculosis. Resistance to $\mathrm{INH}$ arises at a frequency of $10^{-5}-10^{-7}$ comparable to that reported for RMP [5]. RMP is essential in short course chemotherapy regimens as, without it, treatment must be prolonged to 9 or 12 
months to ensure sterilisation of the lesions. In developing countries the management of tuberculosis becomes extremely difficult in the presence of significant RMP resistance. A better understanding of the mechanisms leading to the development of MDR is essential to minimise this problem.

Mechanisms responsible for resistance to the first-line drugs have been the focus of research by many investigators and have been reviewed recently [6]. Resistance to INH develops as a result of mutations in the catalase-peroxidase gene $(k a t \mathrm{G})$ or the $\operatorname{inh} \mathrm{A}$ gene, which encodes an enzyme involved in mycolic acid synthesis. Resistance to ETH may also be mediated by mutations in the inhA gene. RMP resistance is mediated by mutations in the $r p o B$ gene encoding the $\beta$-subunit of RNA polymerase. SM resistance can occur as a result of mutations in either the $r r s$ gene or the $\mathrm{S} 12$ ribosomal protein gene $(r p s \mathrm{~L})$. It has been proposed that resistance in MDR strains is the result of an accumulation of mutations in the gene targets of a specific antibiotic. This may suggest a degree of inherent genome instability in these strains and implies that second-line drugs may also be of limited use, as their use may rapidly lead to resistance to these agents. Given this situation, it is essential that the use of first-line drugs such as INH and RMP be optimised.

To test the genome-instability hypothesis, the genome of serial M. tuberculosis isolates from patients in a high incidence community was studied by DNA fingerprinting and by mutational analysis of genes previously shown to be involved in resistance. The level of in-vitro resistance amongst MDR strains to antituberculosis drugs was also quantified.

\section{Materials and methods}

\section{Clinical isolates and patient data}

Drug-resistant isolates of $M$. tuberculosis ( $\mathrm{n}=85$; group A samples, Table 1) were obtained during the follow-up of 23 patients residing in the Western Cape Province, South Africa, between Oct. 1993 and Aug. 1994 and the degree of in-vitro resistance to antituberculosis drugs was determined quantitatively for INH, RMP, SM and ETH. Follow-up isolates $(n=31$; group B samples, Table 2) from a smaller group of eight patients were subjected to further molecular analysis. DNA fingerprint analysis with the IS6110 probe was performed on all sequential isolates to confirm identity. All patients had evidence of tuberculosis on chest radiography and diagnosis was confirmed by culture of $M$. tuberculosis from sputum. The clinical isolates were resistant to at least one antituberculosis drug as determined by the proportional methods [7]. The susceptibility tests were performed on Löwenstein Jensen (LJ) medium containing critical concentrations (mg/L) of: INH, 0.2 and 1; RMP, 30; rifabutin (RBU),
10 and 20; SM, 5; ETH, 20; EMB, 2; ofloxacin (OF), 2; while kanamycin (KM) at, 5; CS, 50; and $\mathrm{TH}$, $2 \mathrm{mg} / \mathrm{L}$ respectively were incorporated into Middlebrook $7 \mathrm{H} 10$ agar. Although all patients had active tuberculosis for periods longer than indicated in Tables 1 and 2, only the follow-up samples listed here were available and used for this study.

\section{Quantitative drug resistance determination}

The MICs of INH, RMP, SM and ETH were determined by the agar dilution method [8]. Serial dilutions of INH, RMP, SM and ETH were made and incorporated into Middlebrook $7 \mathrm{H} 10$ agar medium. Test organisms, maintained on LJ medium, were inoculated into Dubos broth and incubated for 10 days at $37^{\circ} \mathrm{C}$. The cultures were then adjusted to an optical density of a McFarland no. 1 standard, equivalent to $c$. $2 \times 10^{7}$ organisms $/ \mathrm{ml}$, with a Klett-Summerson colorimeter. Ten $\mu \mathrm{l}$ of each culture were then inoculated (in duplicate) on to drug-containing and drug-free control plates, sealed in plastic bags and incubated at $37^{\circ} \mathrm{C}$ for 21 days. The lowest drug concentration that inhibited the growth of $>99 \%$ of the bacterial population was considered to be the MIC. M. tuberculosis $\mathrm{H} 37 \mathrm{Rv}$ (ATCC 27294) was included as a control. Critical concentrations of $0.2 \mathrm{mg} / \mathrm{L}$ for $\mathrm{INH}, 1 \mathrm{mg} / \mathrm{L}$ for RMP, $2 \mathrm{mg} / \mathrm{L}$ for $\mathrm{SM}$ and $5 \mathrm{mg} / \mathrm{L}$ for ETH were used to discriminate between susceptible and resistant isolates.

\section{Semi-quantitative catalase assays}

Test organisms were grown to an optical density of a McFarland no. 1, standard in $20 \times 150-\mathrm{mm}$ screwcapped tubes containing Dubos medium. One $\mathrm{ml}$ of a mixture $(1: 1)$ of hydrogen peroxide $30 \%$ and Tween 80 $10 \%$ solution, was applied to the surface of growth. After $5 \mathrm{~min}$, the highest level (in $\mathrm{mm}$ ) of the column of $\mathrm{O}_{2}$ bubbles generated was recorded [9]. The H37Rv strain of $M$. tuberculosis and uninoculated tube of medium were included as controls. Additional controls consisted of $M$. avium (ATCC 25291, low catalase) and M. gordonae (ATCC 14470, high catalase).

\section{DNA extraction and fingerprinting}

Sputum samples were grown in a BACTEC TB-460 System (Becton Dickinson, USA) and subcultured on LJ slants. Organisms were heat-killed at $80^{\circ} \mathrm{C}$ for $1 \mathrm{~h}$ before DNA extraction [10] and fingerprinted by restriction fragment-length polymorphism with the IS6110 element as described elsewhere [11].

\section{Mutational analysis}

Primers were synthesised to amplify small regions ( $c$. $200 \mathrm{bp}$ each) of the $k a t \mathrm{G}, \operatorname{inh} \mathrm{A}, r p o \mathrm{~B}, r r s$ and $r p s \mathrm{~L}$ genes (Table 3). A 50-ng sample of DNA from each isolate was amplified in a $100-\mu 1$ reaction mixture and $5 \mu \mathrm{l}$ of the amplified products were subjected to SSCP 
Table 1. Data for MDR isolates (group A)

\begin{tabular}{|c|c|c|c|c|c|c|c|c|}
\hline \multirow[b]{2}{*}{ Patient } & \multirow{2}{*}{$\begin{array}{c}\text { Isolate } \\
\text { no. }\end{array}$} & \multirow[b]{2}{*}{ Date } & \multirow[b]{2}{*}{ Initial resistance patterns ${ }^{*}$} & \multirow{2}{*}{$\begin{array}{c}\text { Catalase } \\
(\mathrm{mm})\end{array}$} & \multicolumn{4}{|c|}{$\mathrm{MIC}(\mathrm{mg} / \mathrm{L})$} \\
\hline & & & & & $\mathrm{INH}$ & SM & RIF & ETH \\
\hline \multirow[t]{3}{*}{ A } & 1 & $2 / 94$ & INH, RMP & 4 & 20 & $<2.5$ & 100 & $<5$ \\
\hline & 2 & $4 / 94$ & INH, RMP & 1 & 20 & $<2.5$ & 100 & $<5$ \\
\hline & 3 & $4 / 94$ & INH, RMP, TH & 16 & 20 & $<2.5$ & 100 & $>5$ \\
\hline B & 12 & $5 / 94$ & INH, RMP, RBU, KM & 0 & $>40$ & $<2.5$ & $>100$ & $<5$ \\
\hline & 11 & $5 / 94$ & INH, RMP, RBU, KM & 0 & $>40$ & $<2.5$ & $>100$ & $<5$ \\
\hline & 10 & $6 / 94$ & INH, RMP & 0 & $>40$ & $<2.5$ & $>100$ & $<5$ \\
\hline $\mathrm{C}$ & 14 & $2 / 94$ & INH, RMP & 5 & 20 & 5 & $>100$ & $<5$ \\
\hline & 17 & $6 / 94$ & INH, RMP & 5 & 10 & 5 & $>100$ & $<5$ \\
\hline $\mathrm{D}$ & 24 & $10 / 93$ & INH, RMP, SM, TH & 5 & 10 & 5 & $>100$ & $<5$ \\
\hline & 28 & $3 / 94$ & INH, RMP, SM, & 1 & 10 & 5 & $>100$ & $<5$ \\
\hline & 25 & $4 / 94$ & INH, RMP, SM, & 5 & 10 & 5 & $>100$ & $<5$ \\
\hline & 26 & $5 / 94$ & INH, RMP, SM, & 5 & 10 & 5 & $>100$ & $<5$ \\
\hline & 27 & $7 / 94$ & INH, RMP, SM, & 4 & 10 & 5 & $>100$ & $<5$ \\
\hline $\mathrm{E}$ & 29 & $12 / 93$ & INH, RMP, KM, TH & 20 & 5 & 10 & $>100$ & 20 \\
\hline & 30 & $12 / 93$ & INH, RMP, KM, TH & 6 & 5 & 10 & $>100$ & 20 \\
\hline & 31 & $4 / 94$ & INH, RMP, SM & 10 & 5 & 20 & $>100$ & 20 \\
\hline & 32 & $5 / 94$ & INH, RMP, SM, ETH & 20 & 5 & 10 & $>100$ & 20 \\
\hline & 33 & $5 / 94$ & INH, RMP, SM, ETH & 17 & 5 & 10 & $>100$ & 20 \\
\hline & 34 & $6 / 94$ & INH, RMP, SM, ETH & 40 & 5 & 10 & $>100$ & 20 \\
\hline $\mathrm{F}$ & 35 & $3 / 94$ & INH, RMP, EMB, RBU, KM TH & 13 & 10 & $<2.5$ & $>100$ & $<5$ \\
\hline & 36 & $4 / 94$ & INH, RMP, EMB, RBU, KM TH & 9 & 10 & $<2.5$ & NA & $<5$ \\
\hline G & 40 & $2 / 94$ & INH, RMP & 7 & 10 & $>1000$ & $>100$ & $<5$ \\
\hline & 42 & $3 / 94$ & INH, RMP, SM & 21 & 10 & $>1000$ & 100 & $<5$ \\
\hline & 41 & $4 / 94$ & INH, RMP, SM & 10 & 10 & $>1000$ & $>100$ & $<5$ \\
\hline & 45 & $6 / 94$ & INH, RMP, SM & 10 & 10 & $>1000$ & $>100$ & $<5$ \\
\hline $\mathrm{H}$ & 46 & $1 / 94$ & INH, RMP, SM, EMB & 45 & 5 & $>1000$ & $>100$ & $<5$ \\
\hline & 50 & $2 / 94$ & INH, RMP, CS, SM, EMB & 19 & 5 & $>1000$ & $>100$ & $<5$ \\
\hline & 47 & $3 / 94$ & INH, RMP, SM, EMB, CS, TH & 16 & 5 & $>1000$ & $>100$ & $<5$ \\
\hline & 48 & $4 / 94$ & INH, RMP, SM, EMB, CS, TH & 3 & 5 & $>1000$ & $>100$ & $<5$ \\
\hline & 49 & $6 / 95$ & INH, RMP, SM, EMB, CS, TH, KM & 2 & 5 & $>1000$ & $>100$ & $<5$ \\
\hline I & 81 & $2 / 94$ & INH, RMP & 1 & 2.5 & $<2.5$ & $>100$ & $<5$ \\
\hline & 78 & $3 / 94$ & INH, RMP, KM & 1 & 2.5 & $<2.5$ & $>100$ & $<5$ \\
\hline & 79 & $3 / 94$ & INH, RMP, EMB, KM & 0 & 2.5 & $<2.5$ & 100 & $<5$ \\
\hline & 83 & $4 / 94$ & INH, RMP, EMB, KM & 2 & 5 & $<2.5$ & $>100$ & $<5$ \\
\hline & 82 & $6 / 94$ & INH, RMP, EMB, RBU, KM & 1 & 2.5 & $<2.5$ & $>100$ & $<5$ \\
\hline & 85 & $7 / 94$ & INH, RMP, RBU, CS, KM & 3 & 5 & $<2.5$ & $>100$ & $<5$ \\
\hline $\mathrm{J}$ & 86 & $1 / 94$ & INH, RMP, SM, KM & $>40$ & 2.5 & 20 & $>100$ & $<5$ \\
\hline & 87 & $2 / 94$ & INH, RMP, SM, KM & 2 & 2.5 & 20 & $>100$ & $<5$ \\
\hline $\mathrm{K}$ & 94 & $3 / 94$ & INH, SM, KM, TH & 9 & 10 & 10 & NA & $<5$ \\
\hline & 95 & $3 / 94$ & $\mathrm{INH}, \mathrm{KM}$ & 13 & 10 & 10 & NA & $<5$ \\
\hline & 96 & $5 / 94$ & INH, RMP, SM, KM & 5 & 10 & 5 & NA & $<5$ \\
\hline $\mathrm{L}$ & 97 & $1 / 94$ & INH, RMP & 5 & 10 & $<2.5$ & $>100$ & $<5$ \\
\hline & 99 & $4 / 94$ & INH, RMP, RBU, KM & 3 & 10 & $<2.5$ & $>100$ & $<5$ \\
\hline M & 110 & $1 / 94$ & INH, RMP, CS & 10 & 5 & $<2.5$ & $>100$ & $<5$ \\
\hline & 103 & $1 / 94$ & INH, RMP & 6 & 5 & $<2.5$ & 100 & $<5$ \\
\hline & 104 & $2 / 94$ & INH, RMP, SM, CS & 4 & 5 & $<2.5$ & NA & $<5$ \\
\hline & 111 & $2 / 94$ & INH, RMP & 4 & 5 & $<2.5$ & $>100$ & $<5$ \\
\hline & 105 & $4 / 94$ & INH, RMP, CS & 6 & 5 & $<2.5$ & NA & $<5$ \\
\hline & 106 & $4 / 94$ & INH, RMP, SM, CS, TH & 4 & 5 & $<2.5$ & $>100$ & $<5$ \\
\hline & 107 & $4 / 94$ & INH, RMP, SM & $>40$ & 5 & NA & $>100$ & $<5$ \\
\hline & 108 & $5 / 94$ & INH, RMP, SM, KM, TH & 20 & 5 & $<2.5$ & NA & $<5$ \\
\hline $\mathrm{N}$ & 113 & $5 / 94$ & INH, RMP & 17 & 2.5 & $<2.5$ & $>100$ & $<5$ \\
\hline & 114 & $5 / 94$ & INH, RMP & 4 & 2.5 & $<2.5$ & NA & $<5$ \\
\hline $\mathrm{O}$ & 117 & $3 / 94$ & INH, RMP, KM & 9 & 5 & $<2.5$ & $>100$ & $<5$ \\
\hline & 119 & $4 / 94$ & INH, RMP, RBU, KM, TH & $>40$ & 5 & $<2.5$ & $>100$ & $<5$ \\
\hline $\mathbf{P}$ & 121 & $2 / 94$ & INH, RMP, SM, EMB & 20 & 10 & $>1000$ & $>100$ & $<5$ \\
\hline & 123 & $3 / 94$ & INH, RMP, SM, KM, TH & 5 & 10 & $>1000$ & $>100$ & $<5$ \\
\hline & 122 & $4 / 94$ & INH, RMP, SM, KM, TH & 12 & 10 & $>1000$ & $>100$ & $<5$ \\
\hline Q & 129 & $5 / 94$ & INH, RMP, SM, RBU & 9 & 5 & $>1000$ & $>100$ & $<5$ \\
\hline & 130 & $5 / 94$ & INH, RMP, SM & 6 & 5 & $>1000$ & $>100$ & $<5$ \\
\hline $\mathrm{R}$ & 134 & $1 / 94$ & INH, RMP, RBU, CS, ETH & $>40$ & 40 & $<2.5$ & $>100$ & $>20$ \\
\hline & 135 & $2 / 94$ & INH, RMP, ETH & $>40$ & 40 & $<2.5$ & $>100$ & $>20$ \\
\hline & 136 & $2 / 94$ & INH, RMP, SM, RBU, CS, ETH & $>40$ & 40 & $<2.5$ & $>100$ & $>20$ \\
\hline & 138 & $3 / 94$ & INH, RMP, SM, RBU, CS, ETH & 17 & 40 & $<2.5$ & $>100$ & 20 \\
\hline & 139 & $3 / 94$ & INH, RMP, SM, ETH & 5 & 40 & $<2.5$ & $>100$ & 20 \\
\hline & 137 & $4 / 94$ & INH, RMP, SM, RBU, CS, KM, ETH & $>40$ & 40 & $<2.5$ & $>100$ & $>20$ \\
\hline $\mathrm{S}$ & 144 & $3 / 94$ & INH, RMP & 5 & 5 & $>1000$ & $>100$ & $<5$ \\
\hline & 142 & $3 / 94$ & INH, SM, RBU, CS, TH & 1 & 5 & $>1000$ & $>100$ & $<5$ \\
\hline & 145 & $4 / 94$ & INH, RMP, SM, TH & 5 & 5 & $>1000$ & $>100$ & $<5$ \\
\hline & 143 & $5 / 94$ & INH, RMP, SM & 6 & 5 & $>1000$ & $>100$ & $<5$ \\
\hline $\mathrm{T}$ & 146 & $1 / 94$ & INH, RMP, SM, EMB, CS & 13 & 5 & $>1000$ & NA & $<5$ \\
\hline & 147 & $2 / 94$ & INH, RMP, SM, EMB, KM & 25 & 5 & $>1000$ & NA & $<5$ \\
\hline & 148 & $3 / 94$ & INH, RMP, SM, EMB, CS, KM & 9 & 5 & $>1000$ & NA & $<5$ \\
\hline
\end{tabular}


Table 1. (continued)

\begin{tabular}{|c|c|c|c|c|c|c|c|c|}
\hline \multirow[b]{2}{*}{ Patient } & \multirow{2}{*}{$\begin{array}{c}\text { Isolate } \\
\text { no. }\end{array}$} & \multirow[b]{2}{*}{ Date } & \multirow[b]{2}{*}{ Initial resistance patterns* } & \multirow{2}{*}{$\begin{array}{c}\text { Catalase } \\
(\mathrm{mm})\end{array}$} & \multicolumn{4}{|c|}{$\mathrm{MIC}(\mathrm{mg} / \mathrm{L})$} \\
\hline & & & & & INH & SM & RIF & $\mathrm{ETH}$ \\
\hline \multirow[t]{3}{*}{$\mathrm{U}$} & 149 & $1 / 94$ & INH, RMP, SM, EMB, CS, KM & 35 & 10 & 100 & $>100$ & $<5$ \\
\hline & 151 & $3 / 94$ & INH, RMP, SM & 12 & 10 & 100 & $>100$ & $<5$ \\
\hline & 152 & $3 / 94$ & INH, RMP, SM, EMB, CS, KM & 11 & 10 & 100 & $>100$ & $<5$ \\
\hline \multirow[t]{2}{*}{ V } & 155 & $1 / 94$ & INH, RMP, KM & 1 & 2.5 & $<2.5$ & 100 & $<5$ \\
\hline & 158 & $3 / 94$ & INH, RMP, KM & 1 & 2.5 & $<2.5$ & $>100$ & $<5$ \\
\hline \multirow[t]{7}{*}{ W } & 160 & $12 / 93$ & INH, RMP, SM, KM & 37 & 10 & 5 & $>100$ & $<5$ \\
\hline & 162 & $1 / 94$ & INH, RMP, SM & $>40$ & 10 & NA & $>100$ & $<5$ \\
\hline & 169 & $3 / 94$ & INH, RMP, SM & 1 & 10 & 5 & $>100$ & $<5$ \\
\hline & 167 & $6 / 94$ & INH, RMP, SM & 4 & 10 & 5 & $>100$ & $<5$ \\
\hline & 166 & $7 / 94$ & INH, RMP, SM & 24 & 10 & 5 & $>100$ & $<5$ \\
\hline & 168 & $7 / 94$ & INH, RMP, SM & 27 & 10 & 5 & $>100$ & $<5$ \\
\hline & 170 & $8 / 94$ & INH, RMP, SM, KM & 13 & 10 & $\mathrm{NA}$ & 100 & $<5$ \\
\hline
\end{tabular}

*Initial resistance patterns were results from the routine screening of INH, Isoniazid; SM, streptomycin; EMB, ethambutol; RBU, rifabutin ETH, ethionamide; RMP, rifampicin; KM, kanamycin; CS, cycloserine; TH, thiacetazone.

NA, not available.

analysis as described previously [12]. A mobility shift with regard to the $M$. tuberculosis $\mathrm{H} 37 \mathrm{Rv}$ reference strain was scored as a mutation which was confirmed by restriction endonuclease digestion in cases where a restriction enzyme site was affected (Table 3 ) or by direct sequencing of the polymerase chain reaction (PCR) product. Direct sequencing of PCR products was performed with the Sequenase PCR Product sequencing kit (United States Biochemical, Cleveland, OH, USA) according to the manufacturer's instructions.

\section{Dot-blot hybridisation for strain $W$}

Previously described primers RTB59 and RTB38 [12] were used to amplify a region around codon 315 in the kat $G$ gene. The amplified products were subjected to separate dot-blot hybridisation assays [13] with radiolabelled oligonucleotides RTB 39 (normal for codon 315, [12]) and RTBmu: dGCGATCACC $A C A-$ GGCATCGA (dinucleotide mutant for codon 315), respectively.

\section{Results}

\section{Treatment and drug resistance patterns}

Patient M (group A patients, Table 1) had the most isolates available for the time period under investigation $(n=8)$ and results from the hospital records for this patient were used as an example to demonstrate the effect of treatment on susceptibility patterns (Table 4). Not unexpectedly, a trend of initial resistance to INH and development of resistance to RMP (and other drugs) was frequently noticed in isolates from patients in this study. Following diagnosis in Sept. 1991, patient M presented with an INH resistant strain in July 1992, which became resistant to RMP after prolonged treatment with the fixed combination of INH, RMP and PZA (Rifater). From Dec. 1993, the treatment was changed to include INH, SM, ETH, EMB, TH and OF and the isolates became resistant to SM, CS, TH and
$\mathrm{KM}$ within the following 5 months, in addition to INH and RMP. It is interesting that although this patient at no time received KM or CS (according to the hospital and clinic records), the organism became resistant to these two antibiotics. Once resistant to INH and RMP, the isolates retained this resistance profile.

\section{MICs}

MICs for INH, RMP, SM and ETH, four of the agents most commonly used in the treatment of tuberculosis and for which the principal molecular mechanisms of resistance have been reported [6], were determined in this study. The results for group A samples show that despite changes that may occur in resistance patterns over time, the MIC for a particular agent stayed constant in follow-up isolates from a particular patient (Table 1). In most cases, the MIC corresponded to the drug resistance patterns obtained during the initial routine screening. The isolates could be grouped into low-level and high-level resistance, based on a low or a high MIC. Isolates from only $2(9 \%)$ of the patients were resistant to high levels of INH (MIC $40 \mathrm{mg} / \mathrm{L}$ ), and $48 \%$ of the patients had isolates that were resistant to levels just above the normal critical concentration for INH (MICs of $0.2-5 \mathrm{mg} / \mathrm{L}$ ). Intermediate resistance (MICs of $10-20 \mathrm{mg} / \mathrm{L}$ for $\mathrm{INH}$ ) was observed for isolates from $10(44 \%)$ of the patients. This is in contrast to the results for RMP, where isolates from 21 (91\%) of the patients had MICs of $100 \mathrm{mg} / \mathrm{L}$, which is far above the normal critical concentration for RMP. Isolates from $7(30 \%)$ of the 23 patients had MICs for $\mathrm{SM}$ of $100->1000 \mathrm{mg} / \mathrm{L}$, isolates from $5(22 \%)$ of the patients had MICs between 5 and $20 \mathrm{mg} / \mathrm{L}$, while 10 (44\%) of the patients were infected with strains susceptible to SM. It was noted that 12 isolates from $2(9 \%)$ of the patients were resistant to ETH with MICs of $20 \mathrm{mg} / \mathrm{L}$ (Table 5). The low frequency of ETH resistance is probably a reflection of the restriction of its use to the management of drug-resistant tuberculosis in this region. 


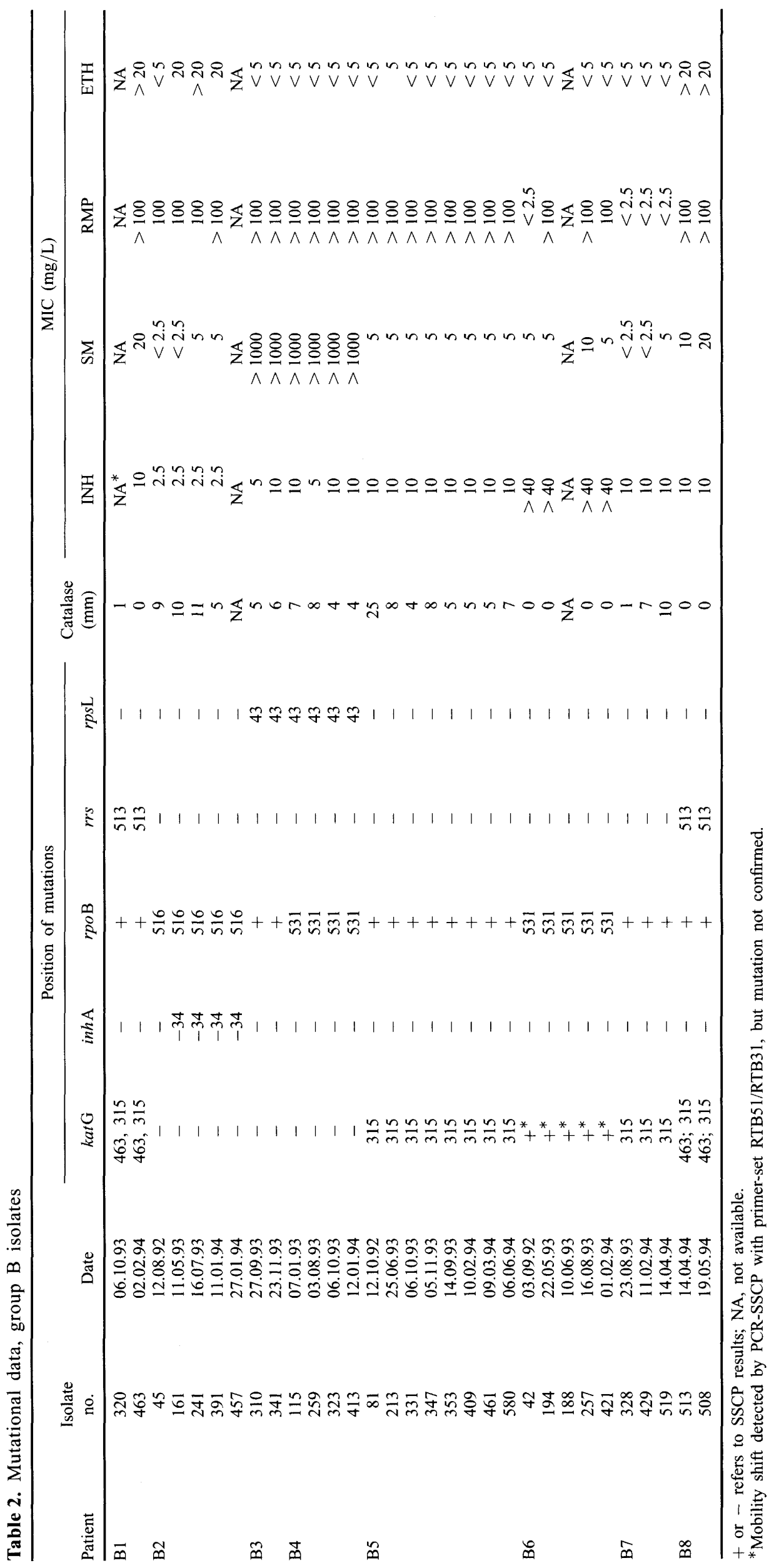


Table 3. Mutational analysis of samples

\begin{tabular}{|c|c|c|c|}
\hline Primer & Sequence & $\begin{array}{l}\text { Restriction } \\
\text { endonuclease }\end{array}$ & Reference \\
\hline $\begin{array}{l}\text { katG } \\
\text { RTB51 } \\
\text { RTB31 }\end{array}$ & $\begin{array}{l}\text { GTGCCCGAGCAACACCCACC } \\
\text { TCAAGTCGACTGGTCGCGAC }\end{array}$ & & 12 \\
\hline $\begin{array}{l}\text { RTB59 } \\
\text { RTB39 }\end{array}$ & $\begin{array}{l}\text { TGGCCGCGGCGGTCGACATT } \\
\text { GCTGGTGATCGCGTCCTTAC }\end{array}$ & & 12 \\
\hline $\begin{array}{l}\text { RTB57 } \\
\text { RTB37 }\end{array}$ & $\begin{array}{l}\text { CCGACGATGCTGGCCACTGA } \\
\text { AGGTCGTGCTGACCGCAGGG }\end{array}$ & & 12 \\
\hline $\begin{array}{l}\text { RTB56 } \\
\text { RTB36 }\end{array}$ & $\begin{array}{l}\text { CCCTGCGGTCAGCACGACCT } \\
\text { TCGGGGTCGTTGACCTCCCA }\end{array}$ & Msp $\mathbf{I}$ & 12 \\
\hline $\begin{array}{l}\text { RTB54 } \\
\text { RTB34 }\end{array}$ & $\begin{array}{l}\text { CTACAAGCGCTTACCGCTGG } \\
\text { GACCTCGACAAGCGCCCGCA }\end{array}$ & Hae III & 12 \\
\hline $\begin{array}{l}\text { RTB59 } \\
\text { RTB38 }\end{array}$ & $\begin{array}{l}\text { GCTGGTGATCGCGTCCTTAC } \\
\text { GGTCAGTGGCCAGCATCGTC }\end{array}$ & HpaII & 12 \\
\hline $\begin{array}{l}\text { katGup51 } \\
\text { katGup32 }\end{array}$ & $\begin{array}{l}\text { GACTACGCCGAACAGCTCC } \\
\text { GCGATAACCCCGCAAGACC }\end{array}$ & & 17 \\
\hline $\begin{array}{l}\text { katGup52 } \\
\text { katGup32 }\end{array}$ & $\begin{array}{l}\text { GCGGGGTTATCGCCGATG } \\
\text { GCCCTCGACGGGGTATTTC }\end{array}$ & & 17 \\
\hline $\begin{array}{l}\text { inhA } \\
\text { inhA51 } \\
\text { inhA31 }\end{array}$ & $\begin{array}{l}\text { CGGGCAACAAGCTCGACGGG } \\
\text { GGGTTCATGATCGGCAGGAG }\end{array}$ & & Current \\
\hline $\begin{array}{l}\text { inhp5 } \\
\text { inhp3 }\end{array}$ & $\begin{array}{l}\text { CGCAGCCAGGGCCTCGCTG } \\
\text { CTCCGGTAACCAGGACTGA }\end{array}$ & & 25 \\
\hline $\begin{array}{l}r p o \mathrm{~B} \\
\text { TR8 } \\
\text { TR9 }\end{array}$ & $\begin{array}{l}\text { TGCACGTCGCGGACCTCCA } \\
\text { TCGCCGCGATCAAGGAGT }\end{array}$ & & 30 \\
\hline $\begin{array}{l}r r s \\
\text { STR51 } \\
\text { STR31 }\end{array}$ & $\begin{array}{l}\text { TTCCTTGGGATCCGTGCCGT } \\
\text { CTAGACGCGTCCTGTGCATG }\end{array}$ & & Current \\
\hline $\begin{array}{l}\text { STR53 } \\
\text { STR33 }\end{array}$ & $\begin{array}{l}\text { TCACCATCGACGAAGCTCCG } \\
\text { CGCCCGCACGCTCACAGTTA }\end{array}$ & $R s a \mathrm{I}, B s r \mathrm{I}, P v u \mathrm{II}$ & Current \\
\hline $\begin{array}{l}r p s L \\
\text { STR52 } \\
\text { STR34 }\end{array}$ & $\begin{array}{l}\text { GTGAAGACCGCGGCTCTGAA } \\
\text { TTCTTGACACCCTGCGTATC }\end{array}$ & MboII, $H p h 1$ & Current \\
\hline
\end{tabular}

Table 4. Effect of treatment on drug resistance patterns for patient $\mathrm{M}^{*}$

\begin{tabular}{lcl}
\hline Treatment & Date of isolation & Drug resistance pattern \\
\hline RIFA & $9 / 91$ & Unknown \\
(Sept. 1991 intermittent until Aug. 1993) & $7 / 92$ & INH \\
& $2 / 93$ & INH \\
& $4 / 93$ & INH \\
& $8 / 93$ & INH, RMP \\
INH, SM, ETH, EMB, TH, OF & $11 / 93$ & INH, RMP \\
(Dec. 1993-) & $12 / 93$ & INH, RMP \\
& $1 / 94$ & INH, RMP, CS \\
& $1 / 94$ & INH, RMP \\
& $2 / 94$ & INH, RMP, CS, SM \\
& $2 / 94$ & INH, RMP \\
& $3 / 94$ & INH, RMP, SM \\
INH, ETH, EMB, TH, OF & $4 / 94$ & INH, RMP, CS \\
(May 1994-) & $4 / 94$ & INH, RMP, CS, SM, TH \\
INH, ETH, EMB, KM, TC, OF, CLO & $4 / 94$ & INH, RMP, SM \\
(June 1994-) & $5 / 94$ & INH, RMP, SM, TH, KM \\
INH, ETH, EMB, TH, KM, Z, OF & & \\
(Oct. 1994-July 1995) & $6 / 94$ & INH, RMP, SM \\
\hline
\end{tabular}

INH, isoniazid; KM, kanamycin; SM, streptomycin; CS, cycloserine; EMB, ethambutol; TH, thiacetazone; RBU, rifabutin; OF, ofloxin; ETH, ethionamide; TC, thiacetozone; RMP, rifampicin; Z, pyrazynamide; RIFA, rifater; CLO, clothamatazine.

${ }^{*}$ Date of first tuberculosis diagnosis: Sept. 1991. 
Table 5. Grouping of MIC results

\begin{tabular}{lccc}
\hline Antituberculosis agent & MIC $(\mathrm{mg} / \mathrm{L})$ & Number of isolates & $\begin{array}{c}\text { Number (\%) of patients } \\
(\mathrm{n}=23)\end{array}$ \\
\hline INH & $\geqslant 40$ & 9 & $2(8.7)$ \\
& $10-20$ & 34 & $10(43.5)$ \\
& $>0.2-\leqslant 5$ & 42 & $11(47.8)$ \\
SM & $100->1000$ & 24 & $7(30.4)$ \\
& $5-20$ & 23 & $6(26.1)$ \\
& Susceptible & 35 & $10(43.5)$ \\
RMP & NA & 3 & $\ldots$ \\
& $\geqslant 100$ & 74 & $21(91.3)$ \\
ETH & NA & 11 & $\cdots$ \\
& $\geqslant 20$ & 12 & $2(8.7)$ \\
& Susceptible & 73 & $21(91.3)$ \\
\hline
\end{tabular}

INH, isoniazid; SM, streptomycin; RMP, rifampicin; ETH, ethionamide; NA, not available.

\section{Isoniazid resistance and catalase activity}

It has been recognised previously that development of resistance to isoniazid is often associated with loss of catalase and peroxidase activities [14] and recent genetic evidence has clearly demonstrated a link between isoniazid resistance and changes in the catalase-peroxidase enzyme [15]. All the isolates in this study were resistant to INH and the catalase activity was reduced in most isolates (compared to H37Rv that had a catalase activity of $40 \mathrm{~mm}$ ). Some isolates ( 10 of 85 ) had normal or even elevated catalase activities, although resistant to INH (Table 1). Particularly interesting to note are isolates from patient $\mathrm{R}$, which were highly resistant to INH $(\mathrm{MIC}=40 \mathrm{mg} / \mathrm{L})$ and yet had normal levels of catalase activity. This suggests a resistance mechanism not involving catalase, confirming previous reports [16]. However, this procedure is semi-quantitative and despite determining catalase activities in duplicate, not all the follow-up isolates from particular patients had the same activity. These discrepancies are currently under further investigation.

\section{DNA fingerprint analysis}

Serial isolates collected from 29 patients with MDR tuberculosis were characterised by DNA fingerprinting with IS6110 [11], Fig. 1 shows a sample result. No fingerprint data are available for isolates from patients $\mathrm{Q}$ and $\mathrm{W}$ in Table 1. Twenty-one strains were identified containing between two (e.g., all isolates from patient 1, Table 1) and 23 (e.g., isolates from patient $\mathrm{O}$, Table 1) insertion elements. Three strains were shown to have infected more than one patient: one strain had 19 IS6110 elements (patients B1 and B8, Table 2), one had four IS6110 elements (patient B5, Table 2; patient $\mathrm{C}$, Table 1) and one had five IS6110 elements (patients B3 and B4, Table 2 and patients G, H, N, P, T, Table 1). No epidemiological data were available for these patients and it is not known whether these infections were due to recent transmission. The banding patterns of 15 of the serial isolates remained constant, demonstrating that the respective infections were due

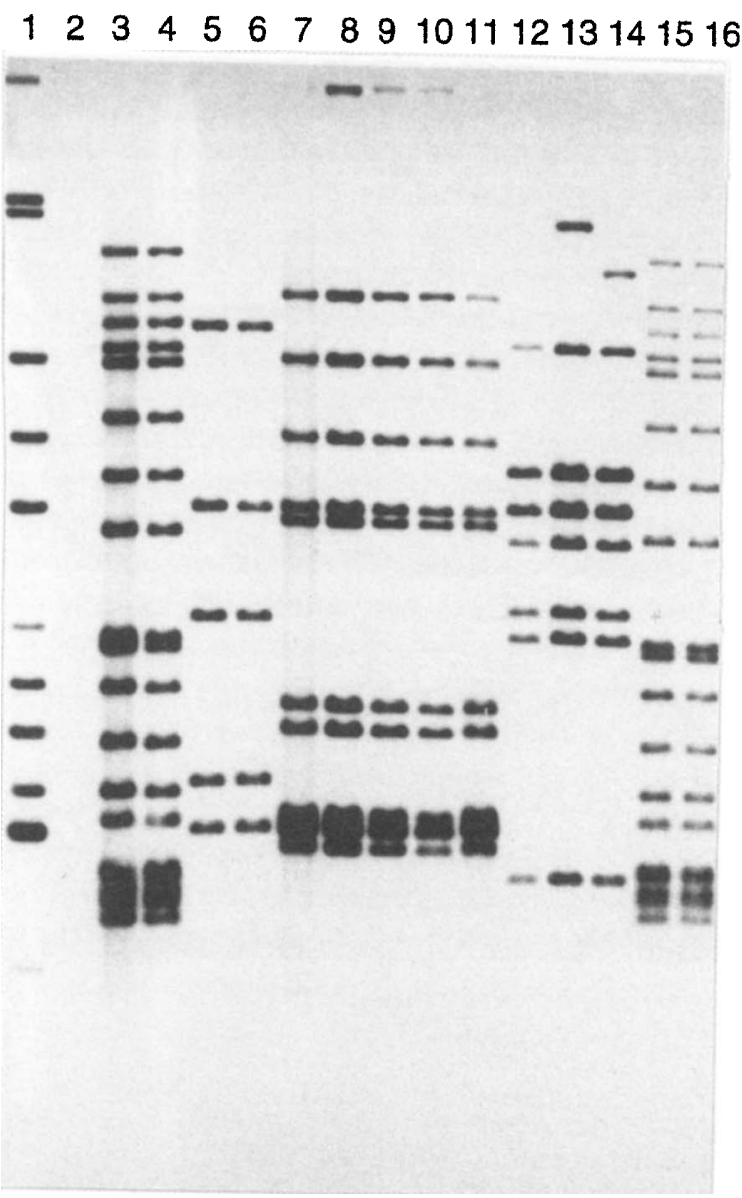

Fig. 1. IS6110 DNA fingerprints. Serial isolates from patients B1 (lanes 3, 4), B3 (5, 6), B6 (7-11), B7 (1214) and $\mathrm{B} 8(\mathbf{1 5}, \mathbf{1 6})$ were fingerprinted with the IS6110 element. Lane 1, control strain MT14323.

to a single strain rather than to multiple infections selected by therapy or re-infection with different strains. Six of the serial isolates (isolates from patients $\mathrm{B} 2$ and B7, Table 2 and isolates from patients A, E, O and $U$, Table 1) showed slight DNA fingerprint perturbations as a function of time. These variations could be either the result of replicative transposition (additional bands) or anomalies in $P v u$ II restriction as 
a result of DNA methylation (band shifts) [16]. These small DNA fingerprint changes do not imply reinfection but rather suggest strain evolution and thus these results suggest that all patients were infected with only a single strain.

\section{Identification of mutations by PCR-SSCP}

Primers were selected to amplify 14 different genetic loci in the group B isolates (Table 2) where mutations that are associated with resistance to INH, ETH, RMP and SM were previously reported. Ten of these loci are in structural genes, while three sets of primers were directed towards putative promoter regions of the katG gene and the $\operatorname{inh} \mathrm{A}$ operon. The results are summarised in Table 2.

Structural genes. The rpoB gene was the most frequently mutated gene in this set of MDR clinical isolates (Table 2). Although the precise nature of the $r p o \mathrm{~B}$ gene mutations was not determined for most isolates in this study, the SSCP analysis suggests that the same mutation is present in sequential isolates from a particular individual, as the nature of the mobility shift remained constant. Sequence analysis indicated that the mobility shifts for all the isolates of patient B2 were due to codon 516 mutations, changing from GAC to GTC, and all the isolates of patients B4 and B6 were due to codon 531 mutations, changing from TCG to TTG.

Mutations were detected in the kat $\mathrm{G}$ gene in isolates from five of eight patients (Table 2). An Arg463Leu mutation has been reported previously $[12,16,18]$ and the presence of this mutation in isolates $320,463,513$ and 508 (Table 2) as initially determined by SSCP analysis, was confirmed by restriction endonuclease analysis with $M s p$ I. No other isolate showed this mutation by SSCP or Msp I analysis. A Ser315Thr mutation was also detected by SSCP and confirmed by Hpa II analysis with primer set RTB59/38 in all isolates from four patients.

Sequential isolates from two patients had both the Arg463Leu and the Ser315Thr mutation. PCR-SSCP analysis of amplified products or RTB51/31 showed the same change in all five sequential isolates of patient B6, but the specific nature of the mutation is as yet unconfirmed. No mutations were detected in the other regions of the $k a t \mathrm{G}$ gene investigated in this study. Complete deletion of the kat $\mathrm{G}$ gene has been proposed as a mechanism of resistance to INH [15], but as several different regions of the gene could be amplified in this study, it can be concluded that none of the samples tested had significant kat $\mathrm{G}$ gene deletions, thus confirming previous reports $[6,12$, 17]. No differences in mutational spectrum were detected in serial isolates. The inh A gene may also be associated with resistance to $\mathrm{INH}$, but no mutations were detected in a 169-bp region of the structural gene that has been shown previously to be involved in resistance to INH and ETH $[19,20]$.

Mutations in both the rrs and $r p s \mathrm{~L}$ genes are associated with resistance to SM and in both cases the mutations are located in two regions of these genes: codons 43 or 88 for $r p s L$ and mutations located near or in codons 530 or 915 of rrs [21]. PCR-SSCP analysis of the rpsL region showed mobility shifts for all the isolates from patients B3 and B4. Restriction endonuclease analysis with $M b o$ II confirmed that the shifts were due to an A to $G$ mutation at codon 43 . No mutations were detected at codon 88 by SSCP or Hph I (codon 88) restriction endonuclease analysis. All the sequential isolates from patients $\mathrm{B} 1$ and $\mathrm{B} 8$ showed an $\mathrm{A}$ to $\mathrm{C}$ mutation at position 513 (confirmed by sequence analysis) of the rrs gene. Restriction endonuclease analysis with $R s a \mathrm{I}$ (position 491) and BsrI (position 512) did not identify any further mutations in the 530 region and no mutations were identified in the 950 region of the rrs gene in this group of MDR isolates.

The mutation at codon 43 in the $r p s \mathrm{~L}$ gene is associated with a high level of resistance (MIC $>1000 \mathrm{mg} / \mathrm{L}$ ) for $\mathrm{SM}$ in isolates from both patients B3 and B4 (Table 2). DNA fingerprint analysis indicated that these two patients were infected with the same strain of $M$. tuberculosis (see DNA fingerprint analysis). It was subsequently found that isolates from patients $\mathrm{G}, \mathrm{H}, \mathrm{P}, \mathrm{T}, \mathrm{Q}$ and $\mathrm{S}$ (Table 1) which had similar MICs for SM, also had the codon 43 mutation. Although isolates from patient $\mathrm{N}$ had fingerprints similar to those of isolates from patients G, H, P and T, they (from patient $\mathrm{N}$ ) not only lacked this mutation, but also had considerably lower MICs. The precise mutation is not yet known.

Isolates from patients $\mathrm{Q}$ and $\mathrm{S}$ also had high MICs for SM. Unfortunately, no fingerprint data were available for isolates from patient Q (see DNA fingerprint analysis), but it was noted that the fingerprint patterns of isolates from patient S (six IS6110 bands) differed by only one additional IS6110 element compared to isolates from patients $\mathrm{G}, \mathrm{H}, \mathrm{N}, \mathrm{P}$ and $\mathrm{T}$ (these had five IS6110 elements). Futhermore, isolates from patients $\mathrm{B} 1$ and B8 (Table 2) also had the same mutations in drug resistance genes and showed the same DNA fingerprint pattern. These data suggest that certain mutations are associated with given levels of resistance and, furthermore, that although DNA fingerprint analysis is a useful technique to monitor the spread of disease, it has no direct diagnostic application, as strains with the same or similar DNA fingerprint patterns may or may not be drug resistant.

Mutations in the putative control elements. To determine whether mutations in control elements of relevant known genes may play a role in drug resistance, a domain spanning c. $400 \mathrm{bp}$ upstream of the kat $\mathrm{G}$ gene 
and c. $300 \mathrm{bp}$ upstream of the ORF1 of the inhA gene locus was analysed by PCR-SSCP. No mutations were detected in the putative $k a t \mathrm{G}$ gene control element. However, four of five sequential isolates from patient B2 showed a mobility shift in the putative control region of the $i n h \mathrm{~A}$ gene (Table 2). Sequence analysis (Fig. 2) confirmed that the mobility shift was due to a novel $\mathrm{C}$ to $\mathrm{T}$ mutation at nucleotide -34 upstream of ORF 1 of the inhA operon. It is important to note that despite the identical fingerprints of all the isolates from this patient, no mutation was detected in isolate 45 , the first isolate collected from this patient, which was susceptible to ETH according to the criteria used in this study. Further analysis of 15 other ETH-resistant isolates from this community failed to show this particular mutation.

\section{Has strain $W$ (New York) spread to our community?}

Some of the MDR strains originating from this community in South Africa have similar drug resistance patterns and a high IS6110 copy number which is similar to the highly drug-resistant $M$. tuberculosis strain $\mathrm{W}$ which has spread from New York to other cities in America and to France [22]. One of the striking features of strain $\mathrm{W}$ is a rare dinucleotide missense mutation at codon 315 (AGC to ACA) of the $k a t \mathrm{G}$ gene [22]. PCR amplification of this region and dot-blot hybridisation assays with radiolabelled oligonucleotides RTB39 (normal for codon 315 [12]) and RTBmu (dinucleotide mutant for codon 315 ) were used to analyse the codon 315 region in one isolate from each of the patients B1-B8 in Table 2. Another 14 MDR isolates, which were not part of isolates in Tables 1 and 2, but which had a high IS6110 copy number, were also examined. All the samples hybridised strongly to oligonucleotide RTB39 and no hybridisation was observed with primer RTBmu under stringent conditions (results not shown), suggesting that none of these isolates belonged to the strain $\mathrm{W}$ family. However, this does not exclude the possibility that other members of this family which have undergone clonal expansion are present in our community [22].

\section{Discussion}

It has been shown previously in limited studies that the DNA fingerprints of $M$. tuberculosis isolates from patients undergoing chemotherapy do not change during the development of resistance [23]. The results of DNA fingerprinting and mutational analysis (14 different loci) in the present study show that the genome of MDR $M$. tuberculosis strains is relatively stable, even while under pressure from different drugs during treatment. Furthermore, the acquisition of resistance to antituberculosis drugs in these patients is not due to secondary infection with a new resistant strain.

$R p o B$ was the most frequently mutated gene in drug resistant $M$. tuberculosis and this gene is a useful target for rapid molecular screening for MDR tuberculosis. There have been many reports on the incidence of mutations in structural genes associated with drug resistance in $M$. tuberculosis [6, 12, 21]. Only the presence and stability of specific mutations in these genes in serial isolates have been investigated in the present study and the results are not an indication of the frequency of the overall mutational pattern in drug-resistance genes in $M$. tuberculosis. However, this study enphasises the importance of confirming strain identity with fingerprint analysis at

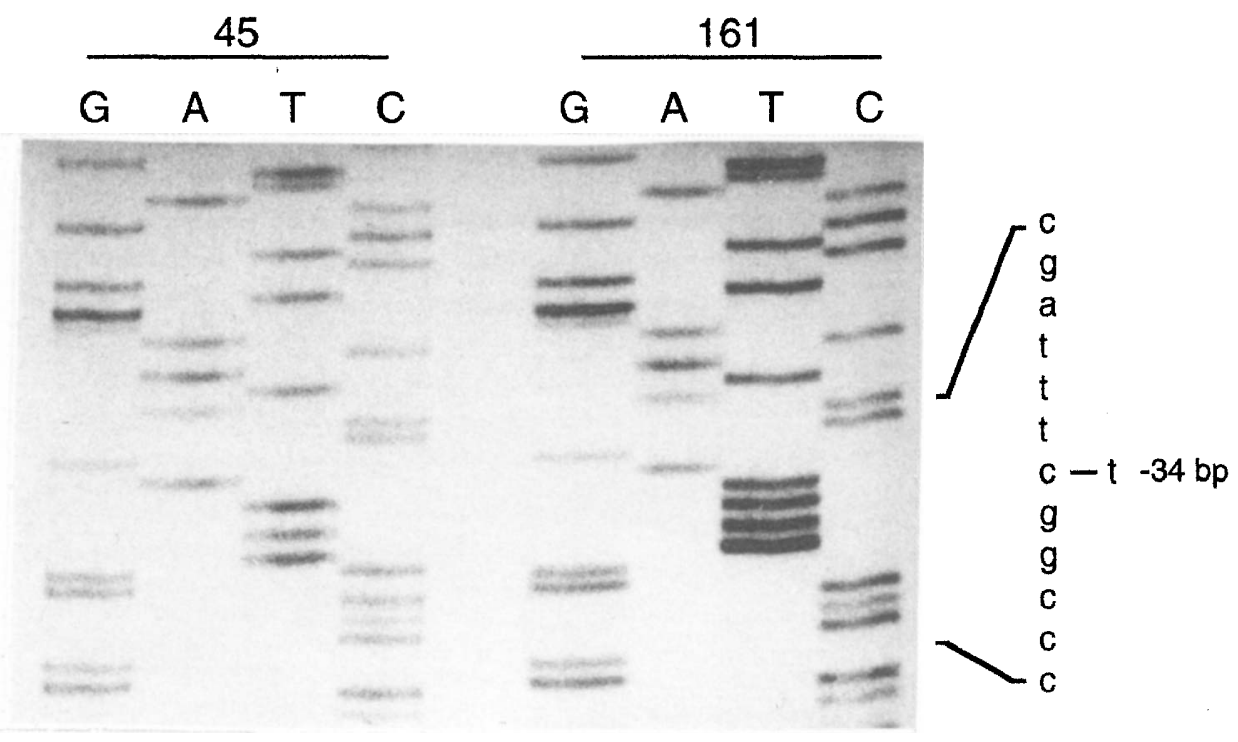

Fig. 2. Mutation in promoter of inhA gene. Isolates 45 and 161 (Table 2) were amplified with primer set inhp5/inhp3 (Table 3) and the PCR products were sequenced directly. A C to T mutation at position -34 bp upstream of ORF1 of the inhA operon was detected in samples 161 and samples 241, 391 and 457 compared to sample 45. 
all times when reporting on the overall incidence of given mutations. This is particularly important when samples originate from a high incidence community for tuberculosis (700/100000 cases/year), such as in South Africa [24] or when samples are analysed retrospectively from a databank.

Mutations in promotor regions of genes can potentially affect expression and, therefore, also contribute towards drug resistance. This possibility was investigated in the kat $\mathrm{G}$ and inhA genes. However, none of the samples showed any mutations in the promoter sequences immediately upstream of the $k a t \mathrm{G}$ gene. This result is consistent with an earlier report where the isolates originated from a different geographical area [17]. In contrast, a novel $\mathrm{C}$ to $\mathrm{T}$ mutation at nucleotide -34 upstream of ORF1 of the inh A operon was detected. This mutation, which has not been described previously, falls within the promotor region of this operon and could affect transcription and drug response, as the first isolate from patient $\mathrm{B} 2$ did not have the mutation at position $-34 \mathrm{bp}$ and only this isolate in the batch from one patient was susceptible to ETH. Mutations $1 \mathrm{bp}$ on either side of a putative ribosome binding site of ORF 1 in $\operatorname{inh} \mathrm{A}$ have been reported $[6,25]$, and although we have found the same mutations in other South African isolates (results not shown), these mutations were not detected in these particular isolates. Results from this study support accumulated evidence $[6,19,25]$ that mutations in the structural region of the $\operatorname{inh} \mathrm{A}$ gene are rare. Although mutations in the promotor region have been described in this paper and by others, few ETH-resistant samples have these promotor mutations. However, recent biochemical and genetic evidence suggests that $\operatorname{inh} \mathrm{A}$ may not be the major target for activated INH in $M$. tuberculosis [26] and may explain why only some of the isolates have inh A mutations.

Accurate drug susceptibility testing of $M$. tuberculosis by conventional techniques is difficult and may perhaps explain the intermittent resistance patterns in follow-up isolates observed in this study. The development of antituberculosis drug resistance is best prevented by combination chemotherapy administered under direct observation. Failure to comply with this requirement on the part of the health services or the patient may lead to monotherapy. The use of combinations of drugs that do not offer optimal protection against the selection of drug-resistant mutants may also elicit resistance in some instances. This study illustrates the manner in which the sequential addition of drugs to the therapeutic regimen can be followed by the accumulative acquisition of resistance.

It is significant that despite changes in drug resistance patterns that occurred during treatment, the level of resistance (based on MICs) for a particular antibiotic remained constant in our patients. This has been observed previously [27] and is an important consideration for treatment, as the results show that although the MICs are above the normal in-vitro critical concentrations for $M$. tuberculosis, a significant number of these organisms have MICs at achievable in-vivo concentrations and patients may still respond to treatment with these antibiotics, particularly if higher, but still clinically acceptable dosages of agents are used. The low MICs found in $c$. $50 \%$ of the $\mathrm{INH}$-resistant isolates indicate that this agent, given in a higher dose, may still be active in many MDR tuberculosis patients [28]. Evidence from early clinical trials in which INH was used as the sole agent in patients with INH-resistant organisms suggests that the use of higher dosages of INH in patients with lower levels of resistance may be clinically beneficial [27]. However, it is known that the rate of elimination of INH is under genetic control $[29,30]$ and varies greatly from one individual to another. The rate of acetylation should therefore be taken into account in evaluating the activity of INH in MDR tuberculosis.

It is noteworthy that almost half of the isolates evaluated in this study were susceptible in vitro to concentrations of INH which are easily achievable, even in rapid acetylators of INH. As INH is relatively inexpensive compared to other drugs available for the management of MDR tuberculosis, we suggest that MIC (INH) testing of drug resistant strains of $M$. tuberculosis should be considered and that, where appropriate, INH should be included in any multidrug regimen for the treatment of MDR tuberculosis [28]. Given the limited number of drugs available for the management of MDR tuberculosis and the increased costs and toxicity associated with their use, it is important to take note of existing drugs that could possibly be used in a mutidrug regimen to treat a signficant proportion of the cases detected.

We gratefully acknowledge the Glaxo-Wellcome Action TB initiative and Tygerberg Hospital for financial assistance.

\section{References}

1. Edlin BR, Tokars JI, Grieco $\mathrm{MH}$ et al. An outbreak of multidrug-resistant tuberculosis among hospitalized patients with acquired immunodeficiency syndrome. $N$ Engl $J \mathrm{Med}$ 1992; 326: 1514-1521.

2. Small PM, Shafer RW, Hopewell PC et al. Exogenous reinfection with multidrug-resistant Mycobacterium tuberculosis in patients with advanced HIV infection. $N$ Engl J Med 1993; 328: $1137-1144$.

3. Hinshaw HC, Feldman WH. Streptomycin in treatment of clinical tuberculosis: preliminary report. Proc Staphy Med Mayo Clinic 1945; 20: 313-318.

4. Medical Research Council. Streptomycin treatment of pulmonary tuberculosis. BMJ 1948; 2: 769-782.

5. Yew WW, Chau CH. Drug-resistant tuberculosis on the 1990s. Eur Respir J 1995; 8: 1184-1192.

6. Musser JM. Antimicrobial agent resistance in mycobacteria: molecular genetic insights. Clin Microbiol Rev 1995; 8: $496-514$

7. Heifets LB. Drug susceptibility tests and the outcome of 
chemotherapy. In: Heifets LB, (ed) Drug susceptibility in the chemotherapy of mycobacterial infections. CRC Boca Raton, Fl, Press Inc.: 1-11.

8. National Committee for Clinical Laboratory Standards. Antimicrobial susceptibility testing. Document M24-P. Villanova, PA, National Committee for Clinical Laboratory Standards. 1990.

9. Kent PT, Kubica GP. Public health mycobacteriology. A guide for the level III laboratory. Atlanta, Centers for Disease Control. 1985: 81-82.

10. Wiid IJF, Werely C, Beyers N, Donald P, van Helden PD. Oligonucleotide (GTG)5 as a marker for Mycobacterium tuberculosis strain identification. J Clin Microbiol 1994; 32: $1318-1321$.

11. Warren R, Hauman $\mathrm{J}$, Beyers $\mathrm{N}$ et al. Unexpectedly high strain diversity of Mycobacterium tuberculosis in a high-incidence community. S Afr Med J 1996; 86: 45-49.

12. Pretorius GS, van Helden PD, Sirgel F, Eisenach KD, Victor TC. Mutations in kat $\mathrm{G}$ gene sequences in isoniazid-resistant clinical isolates of Mycobacterium tuberculosis are rare. Antimicrob Agents Chemother 1995; 39: 2276-2281.

13. Victor T, Du Toit R, Jordaan AM, Bester AJ, van Helden PD. No evidence for point mutations on codons 12,13 , and 61 of the ras gene in a high-incidence area for esophageal and gastric cancers. Cancer Res 1990; 50: 4911-4914.

14. Middlebrook G. Isoniazid-resistance and catalase activity of tubercle bacilli: preliminary report. Am Rev Tuberc 1954; 69: $471-472$.

15. Zhang Y, Heym B, Allen B, Young D, Cole S. The catalaseperoxidase gene and isoniazid resistance of Mycobacterium tuberculosis. Nature 1992; 358: 591-593.

16. van Soolingen D, de Haas PEW, Blumenthal RM et al. Hostmediated modification of PvulI restriction in Mycobacterium tuberculosis. J Bacteriol 1996; 178: 78-84.

17. Heym B, Alzari PM, Honoré N, Cole ST. Missense mutations in the catalase-peroxidase gene, $k a t \mathrm{G}$, are associated with isoniazid resistance in Mycobacterium tuberculosis. Mol Microbiol 1995; 15: 235-245.

18. Cockerill FR, Uhl JR, Temesgen $\mathrm{Z}$ et al. Rapid identification of a point mutation of the Mycobacterium tuberculosis catalase-peroxidase $(k a t \mathrm{G})$ gene associated with isoniazid resistant. J Infect Dis 1995; 171: 240-245.

19. Ristow M, Möhlig M, Rifai M, Schatz H, Feldmann K, Pfeiffer
A. New isoniazid/ethionamide resistant gene mutation and screening for multidrug-resistance Mycobacterium tuberculosis strains. Lancet 1995; 346: 502-503.

20. Banerjee A, Dubnau E, Quemard A et al. $\operatorname{inh} \mathrm{A}$, a gene encoding a target for isoniazid and ethionamide in Mycobacterium tuberculosis. Science 1994; 263: 227-230.

21. Sreevatsan S, Pan X, Stockbauer KE, Williams DL, Kreisworth $\mathrm{BN}$, Musser JM. Characterization of $r p s \mathrm{~L}$ and $r r s$ mutations in Streptomycin-resistant Mycobacterium tuberculosis isolates from diverse geographical localities. Antimicrob Agents Chemother 1996; 40: 1024-1026.

22. Bifani PJ, Plikaytis BB, Kapur V et al. Origin and interstate spread of a New York city multidrug-resistant Mycobacterium tuberculosis clone family. JAMA 1996; 275: 452-457.

23. Godfrey-Faussett P, Stoker NG, Scott JAG, Pasvol G, Kelly P, Clancy L. DNA fingerprints of Mycobacterium tuberculosis do not change during the development of rifampicin resistance. Tuber Lung Dis 1993; 74: 240-243.

24. Fisher S. Western Cape Regional Services Council: Annual Report of the Department of Health Services, South Africa. 1990: 35-51.

25. Morris S, Bai GH, Suffys P, Portillo-Gomez L, Fairchok M, Rouse D. Molecular mechanisms of multiple drug resistance in clinical isolates of Mycobacterium tuberculosis. J Infect Dis 1995; 171: 954-960.

26. Mdluli K, Sherman DR, Hickey MJ et al. Biochemical and genetic data suggest that $\operatorname{inh} A$ is not the primary target for activated isoniazid in Mycobacterium tuberculosis. J Infect Dis 1996; 174: 1085-1090.

27. Devadatta S, Bhatia AL, Andrews RH et al. Response of patients infected with isoniazid-resistance tubercle bacilli to treatment with isoniazid plus PAS or isoniazid alone. Bull World Health Organ 1961; 25: 807-829.

28. Moulding TS. Should isoniazid be used in the retreatment of tuberculosis despite acquired isoniazid resistance? Am Rev Respir Dis 1981; 123: 262-264.

29. Mashimo M, Suzuki T, Abe M, Deguchi T. Molecular genotyping of $\mathrm{N}$-acetylation polymorphism to predict phenotype. Hum Genet 1992; 90: 139-143.

30. Parkin DP, Vandenplas S, Botha FJ et al. Trimodality of Isoniazid elimination: phenotype and genotype in patients with tuberculosis. Am J Respir Crit Care Med 1996 (in press). 